\title{
Author Correction: Determinants of genetic variation across eco-evolutionary scales in pinnipeds
}

Claire R. Peart (D), Sergio Tusso (D), Saurabh D. Pophaly, Fidel Botero-Castro (D), Chi-Chih Wu, David Aurioles-Gamboa, Amy B. Baird, John W. Bickham (D), Jaume Forcada (D), Filippo Galimberti (D), Neil J. Gemmell(D), Joseph I. Hoffman (D), Kit M. Kovacs, Mervi Kunnasranta, Christian Lydersen, Tommi Nyman, Larissa Rosa de Oliveira, Anthony J. Orr, Simona Sanvito (D), Mia Valtonen (iD, Aaron B. A. Shafer (D) and Jochen B. W. Wolf (i)

Correction to: Nature Ecology \& Evolution https://doi.org/10.1038/s41559-020-1215-5, published online 8 June 2020.

In Supplementary Table 6 of this Article originally published, some of the entries in the 'species' column were mistakenly attributed to entries in the 'individuals' column, and some species were missing and incorrectly represented by other species. These errors have now been corrected and the updated Supplementary Tables file containing the corrected Supplementary Table 6 is available online.

Published online: 14 July 2021

https://doi.org/10.1038/s41559-021-01529-6

(c) The Author(s), under exclusive licence to Springer Nature Limited 2021 